ENCYCLOPÉDIE Encyclopédie berbère

BERBERE

3 | 1986

3 | Ahaggar - Alī ben Ghaniya

\title{
Aït-Amrane Mohammed, Idir
}

S. Chaker

\section{OpenEdition}

Journals

Édition électronique

URL : http://journals.openedition.org/encyclopedieberbere/2383

DOI : 10.4000/encyclopedieberbere.2383

ISSN : 2262-7197

\section{Éditeur}

Peeters Publishers

\section{Édition imprimée}

Date de publication : 1 juillet 1986

Pagination : 386-387

ISBN : 2-85744-260-2

ISSN : 1015-7344

\section{Référence électronique}

S. Chaker, « Aït-Amrane Mohammed, Idir », Encyclopédie berbère [En ligne], 3 | 1986, document A130, mis en ligne le 01 décembre 2012, consulté le 13 octobre 2020. URL : http://journals.openedition.org/ encyclopedieberbere/2383; DOI : https://doi.org/10.4000/encyclopedieberbere.2383

Ce document a été généré automatiquement le 13 octobre 2020

(C) Tous droits réservés 
Aiit-Amrane Mohammed, Idir

S. Chaker 

Il appartient au groupe de jeunes Algériens du Lycée de Ben-Aknoun (Alger) qui, à partir de 1945, vont essayer d'intégrer la dimension berbère dans la revendication nationaliste. Sa première sensibilisation politique s'est produite à partir des années 1941-42 dans le cadre des Scouts Musulmans Algériens, contrôlés par le Mouvement National. Aït-Amrane ne semble pas être intervenu dans la crise «berbériste» de 1948-49 qui secoua le P.P.A.-M.T.L.D. et se solda par l'exclusion des « berbéristes ». Mais il a joué un rôle décisif dans la production de chants nationalistes en langue berbère.

3 Il a composé, entre 1945 et 1954, au moins une quinzaine de chants engagés de marche ou de groupe dans lesquels la référence à la langue et à la culture berbères est fortement présente. On citera parmi les plus connus (et encore bien vivants) :

-kker a mmi-s umaziץ! « Debout enfants de Berbère !» (1945)

- yuriyiwen umeddakwel (1947)

«J'avais un camarade (adaptation d'un poème allemand de Uhland. En hommage à Laïmeche Ali qui venait de mourir).

- tigerylanit « L'Internationale » (adaptation kabyle)

Cette production «berbéro-nationaliste » à laquelle Aït-Amrane a fortement contribué marque le début des efforts de planification linguistique axée sur la recherche de systèmes de notation usuels et surtout sur l'enrichissement et la modernisation du lexique. C'est de cette époque que datent de nombreux néo-logismes socio-politiques. Ait-Amrane participera activement à cette entreprise dans laquelle des Kabyles iront puiser en touareg, au Mzab ou en chleuh des unités lexicales ou créeront des formes nouvelles à partir des matériaux kabyles.

5 Aït-Amrane est arrête et emprisonné de 1956 à 1958. A sa libération, il prépare une licence d'arabe qu'il achève en 1961. Il est député à la première Assemblée Nationale algérienne (1963), puis il entame une carrière dans l'Education Nationale qui le mènera jusqu'au stade de Directeur de l'Education d'une wilaya.

\section{BIBLIOGRAPHIE}

BENBRAHIM M. La poésie populaire kabyle et la résistance à la colonisation de 1830 à 1962. Paris, EHESS, 1982 (thèse de 3ème cycle).

\section{INDEX}

Mots-clés : Algérie (partie nord), Biographie, Histoire contemporaine 